\title{
RIOS URBANOS: CONTRIBUIÇÕES DA ANTROPOGEOMORFOLOGIA E DOS ESTUDOS SOBRE OS TERRENOS TECNOGÊNICOS
}

\author{
André Souza Pelech ${ }^{1}$; Maria Naíse de Oliveira Peixoto² \\ 1/nstituto Brasileiro de Geografia e Estatística (IBGE); \\ 2Universidade Federal do Rio de Janeiro
}

\begin{abstract}
Resumo
Os rios urbanos constituem atualmente um desafio para a gestão territorial e ambiental no Brasil. $\mathrm{O}$ alto grau de modificação e poluição dos canais fluviais tem efeitos nos processos geomorfológicos atuantes e em seus controles de funcionamento, sendo necessárias novas abordagens de análise para compreender a dinâmica fluvial destes ambientes. Nesse sentido, a Antropogeomorfologia e os estudos sobre os Terrenos Tecnogênicos se mostram fundamentais para a compreensão da dinâmica fluvial urbana, sendo também a incorporação de elementos antropogênicos nas estruturas de classificação de rios e no mapeamento de feições geomorfológicas fluviais uma abordagem importante para este fim. No entanto, as políticas e projetos de restauração de rios urbanos devem abranger não somente estas novas abordagens geomorfológicas, mas também a necessidade de refuncionalização e ressignificação social, para que a sociedade os reconheça, valorize e proteja.
\end{abstract}

Palavras-chave: Antropogeomorfologia; terrenos tecnogênicos; geomorfologia fluvial; classificação de rios; restauração fluvial.

\begin{abstract}
Urban rivers present a challenge for territorial and environmental management in Brazil. The high degree of modification and pollution of river channels changes geomorphological processes and their functional controls, requiring new approaches for understand fluvial dynamics on urban environments. In that context, the Anthropogeomorphology and the technogenic landforms studies are essencial for understanding urban river dynamics. Furthermore, recent incorporation of anthropogenic elements into river classification structures and fluvial geomorphological mapping is an important approach for this purpose. However, uban river restoration policies and projects must encompass not only these new geomorphological approaches, but also the need for re-functionalization and social resignification, so that society recognizes, values and protects urban rivers.
\end{abstract}

Key words: Anthropogeomorphology; technogenic landforms; fluvial geomorphology; river classification; river restoration. 


\section{1) Introdução}

$\mathrm{O}$

Brasil experimentou uma grande mudança na concentração espacial da sua população, durante a segunda metade do século XX e início do XXI, saindo de um padrão de ocupação marcadamente rural para um predominantemente urbano (IBGE, 2019; Figura 1). Este processo gerou uma inédita pressão sobre o meio físico e os ecossistemas nos sítios urbanos, através de uma intensa modificação da paisagem. A expansão urbana se deu, em geral, distanciada de uma preocupação com os aspectos ambientais, o que muitas vezes é atribuído a um crescimento "desordenado".

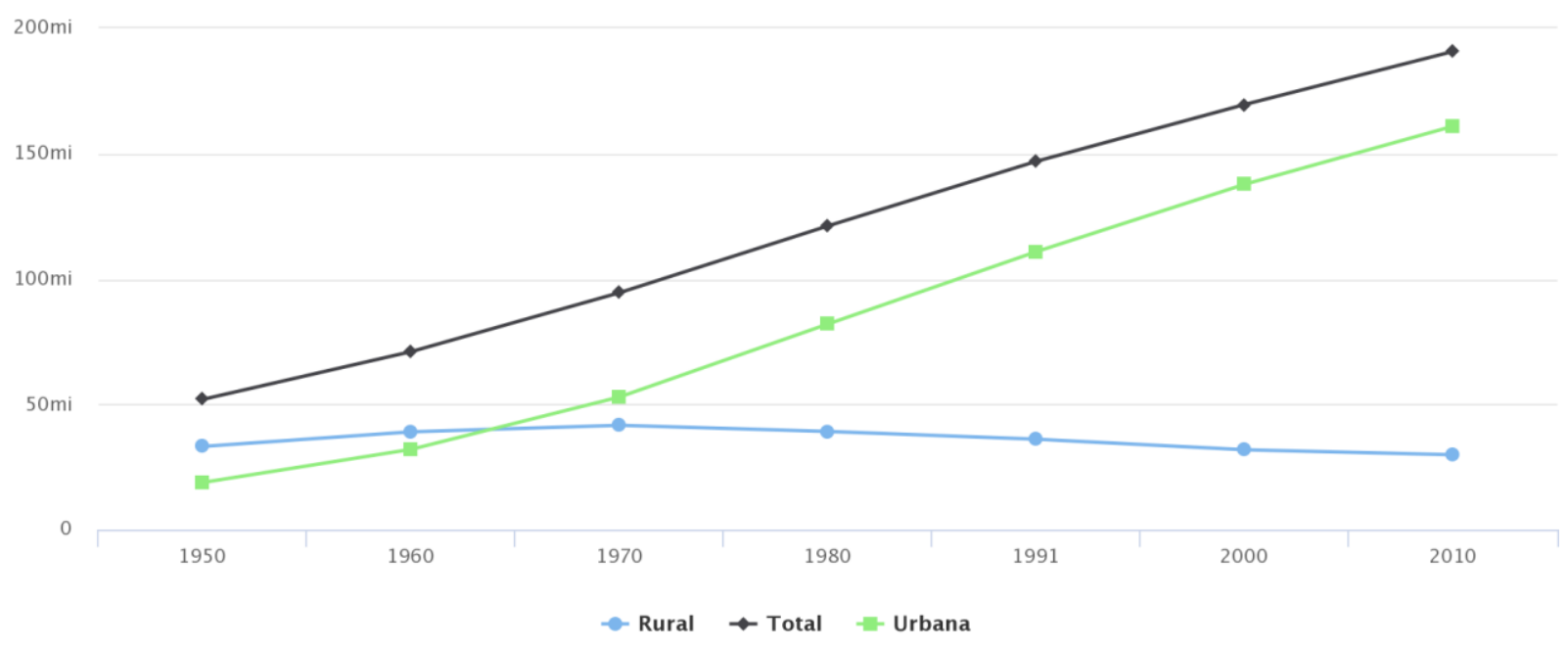

Figura 1. População por situação de domicílio entre os anos de 1950 e 2010 (IBGE, 2019).

Neste contexto, as bacias hidrográficas e os sistemas fluviais têm sido fortemente impactados pelo crescente uso dos seus recursos, para diversas finalidades e atendendo a interesses de agentes e grupos específicos. Macklin e Lewin (2020) apontam a urbanização, a industrialização e a agricultura intensiva como vetores de grande transformação dos sistemas fluviais, provocando impactos em escala global e modificando os modos de vida das sociedades. A retirada da cobertura vegetal original seguida pela implantação do tecido urbano elimina, por exemplo, uma complexa interação entre a água da chuva, a vegetação e a serapilheira, que envolve processos como a interceptação da água pela copa das árvores, o escoamento pelo tronco, o gotejamento pelas folhas, a evapotranspiração, a infiltração e outros diversos tipos de fluxos (BOTELHO, 2011). Neste novo ambiente, a diversidade de caminhos percorridos pelas águas pluviais em um sistema com vegetação natural tende a ser reduzida ao binômio escoamento-infiltração, frequentemente com predominância do primeiro, já que a impermeabilização dos solos provocada pelas pavimentações e pelos equipamentos urbanos propicia o aumento do escoamento superficial (BOTELHO, 2011.). Decorrem dessas mudanças, em grande parte, o aumento de problemas relacionados à intensificação dos episódios de inundações e alagamentos, bem como da evasão de 
sedimentos das encostas para os canais fluviais. Cidades e núcleos urbanos frequentemente apresentam, ainda, problemas relacionados à poluição dos rios, à redução da disponibilidade de águas para uso, à degradação dos ecossistemas, ao aumento das taxas de erosão ou assoreamento, dentre vários outros associados ao padrão de ocupação e uso dos recursos naturais, os quais já vêm sendo fartamente documentados e analisados em estudos científicos e aplicados.

Fruto de processos físico-naturais e também dos agentes sociais atuantes, o relevo associa-se, nesse contexto, a diferentes momentos históricos, econômicos e sociais (JORGE, 2011), sendo por isso destacado, por alguns grupos de geógrafos físicos, a necessidade de dar maior atenção crítica a aspectos das relações sociais e de poder, combinados ao conhecimento das ciências físicas e biológicas, com o propósito de transformação social e ambiental - abordagem que tem sido denominada de Geografia Física Crítica (LAVE et al., 2018; 2019). Esta perspectiva não é recente, como pode ser observado, por exemplo, em James e Marcus (2006), ao analisarem o evento Man's Role in Changing the Face of the Earth Symposium, realizado em 1955, em que identificam uma série de contribuições para a adoção de métodos e práticas interdisciplinares por geomorfólogos, para um entendimento integrado das interações humanas com os sistemas terrestres.

Contudo, percebe-se que os rios urbanos têm sido fortemente relegados nos estudos de Geografia Física, em parte por se inserirem em áreas "muito degradadas", preteridas em relação aos ambientes mais próximos das condições naturais pela maior facilidade de observação, nestes últimos, de processos geomorfológicos de amplo espectro temporal. As paisagens significativamente alteradas pela ação humana são vistas em geral como comuns (e não "extraordinárias", ou exemplares de condições ambientais naturais diferenciadas), desagradáveis ou desinteressantes, sendo, deste modo, frequentemente negligenciadas nas investigações realizadas por geógrafos físicos, como aponta Urban (2018). Nesse sentido, os rios configuram-se como personagens centrais nos debates sobre o Antropoceno (GIBLING, 2018), tendo em vista que boa parte das atividades humanas se dá sobre canais fluviais e planícies de inundação.

Além disso, as modificações humanas que resultam na degradação ou na diminuição da heterogeneidade, da conectividade e da dinâmica fluvial tendem a simplificar os ecossistemas fluviais, reduzindo a oferta de serviços ecossistêmicos (LARGE et al., (2018). Gurnell et al. (2007), por exemplo, apontam diversos impactos do crescimento urbano sobre os processos e formas dos ambientes fluviais, em diferentes escalas espaciais. Na escala da bacia hidrográfica, as áreas urbanas transformam o sistema hidrológico através da construção de superfícies impermeáveis e sistemas de drenagem de águas pluviais. Na escala do canal, os impactos urbanos se dão no reforço das margens e leitos, na modificação do perfil longitudinal e da forma em planta dos rios, na desconectividade hidrológica entre canal e planície e na modificação da vegetação ripária.

A magnitude do fenômeno urbano, com a formação e expansão das grandes cidades e as significativas alterações na morfologia e dinâmica das paisagens (SANTOS FILHO, 2011), tem levado ao desenvolvimento de novas abordagens de análises geológicas e geomorfológicas para o contexto das cidades. Neste contexto se inserem as pesquisas realizadas no âmbito do que vem sendo chamado de Antropogeomorfologia, um campo da Geomorfologia voltado ao estudo da influência humana na geração e modificação das formas de relevo. Conforme destacam Rodrigues (2005) e Rodrigues et al. (2019), a ação humana tem a capacidade de modificar tanto as 
propriedades e a localização dos materiais superficiais como as taxas e balanços dos processos, e ainda de gerar, direta e indiretamente, morfologias específicas, antropogênicas. Estas mudanças também têm sido alvo de estudos voltados ao reconhecimento e mapeamento de feições e depósitos denominados tecnogênicos, inseridos em uma abordagem geológica-geomorfológica com enfoque nos registros das alterações cuja gênese foi/é de origem técnica, que estão materializados na superfície terrestre geralmente com uma abrangência espacial local e/ou regional, e que possuem desdobramentos e conexões com a evolução do relevo em diferentes escalas temporais (OLIVEIRA et al., 2005; MELLO, 2006; OLIVEIRA; PELOGGIA, 2014; PELOGGIA et al., 2014; dentre outros).

Considerando-se que as mudanças produzidas pelas sociedades humanas continuam a promover transformações ambientais, tanto previsíveis como imprevisíveis, que por sua vez as afetam em diferentes intensidades e escalas, e ainda que muitas das pesquisas em andamento buscam criar estruturas teóricas e metodológicas que respondam aos desafios existentes, conforme destaca Kelly (2018), torna-se necessário apreender as alterações nas formas e nos processos físicos e biológicos presentes em diferentes ambientes, assim como nos processos socioculturais que dirigem e se materializam por meio destas mudanças. Deste modo, o presente artigo pretende discutir o papel da Antropogeomorfologia e dos estudos sobre as formas e depósitos tecnogênicos no âmbito dos rios urbanos brasileiros, apresentando também algumas abordagens da geomorfologia fluvial que têm procurado incorporar elementos antropogenéticos nas análises geomorfológicas de canais fluviais.

\section{2) Antropogeomorfologia e Terrenos Tecnogênicos}

O termo Antropogeomorfologia, conforme Goudie e Viles (2016), foi criado para denominar o papel da ação humana na construção de formas de relevo e na modificação da operação dos processos geomorfológicos, tratando, portanto, de muitas das questões-chave dos processos geomorfológicos inseridos no Antropoceno. Segundo Rodrigues (2005) e Rodrigues et al. (2019), , a Antropogeomorfologia surge diante da percepção da magnitude da intervenção humana na superfície terrestre e da necessidade de superar abordagens metodológicas focadas exclusivamente nos elementos ditos "naturais", através de um tratamento simultâneo e sistemático destas intervenções.

Sendo uma subdisciplina da Geomorfologia, a Antropogeomorfologia tem enfrentado, entretanto, como aponta Hupy (2017), algumas dificuldades de crescimento como campo científico, em grande medida devido à complexidade envolvida no estabelecimento de conceitos e métodos de estudo das conexões entre os processos geomorfológicos naturais e os antropogeomorfológicos. Os geomorfólogos que atuam neste campo, segundo o autor citado, dedicam-se ao estudo de todos os agentes de esculturação do relevo (água, vento, gelo, gravidade, plantas e animais) analisados nas pesquisas geomorfológicas tradicionais, ao mesmo tempo que buscam relacioná-los com as atividades dos grupos humanos, tomados como agentes geomorfológicos. Neste contexto, devem ser consideradas tanto as feições geomorfológicas criadas diretamente por processos antropogênicos, geralmente mais evidentes na topografia e geradas deliberadamente por processos remoção e transporte de materiais (como por exemplo: escavação, mineração, construção de ro- 
dovias, dentre outras); como as feições produzidas por processos antropogênicos indiretos, em geral mais difíceis de serem reconhecidos por envolverem a aceleração de processos geomorfológicos naturais, mais do que a criação de novos processos, apresentando assim, por outro lado, geralmente grande expressividade espacial (GOUDIE; VILES, 2016; HUPY, 2017).

A discussão sobre os processos e os produtos relacionados à ação humana também vem sendo desenvolvida, ao longo das últimas décadas, inseridas em estudos geológicos e geomorfológicos ligados à geotecnogênese, compreendendo diferentes níveis de abordagem: a modificação do relevo e as alterações físiográficas (relevos tecnogênicos); as alterações da fisiologia das paisagens (criação, indução, intensificação ou modificação do comportamento dos processos da dinâmica externa); e criação de depósitos superficiais (depósitos correlativos), produzindo marcos estratigráficos. Assim, neste conjunto de pesquisas a ação técnica humana é incorporada como agente modificador das funcionalidades e das formas de relevo, estando estas relacionadas a modos e intensidades diferentes de ação, trazendo implícita a ideia de uma diferenciação dentro das trajetórias de evolução geológica-geomorfológica (PELOGGIA, 1997; OLIVEIRA, 1994; OLIVEIRA et al., 2005; MELLO, 2006; PELOGGIA et al., 2019; entre outros).

Estudos conduzidos nesta abordagem têm produzido investigações empíricas e reflexões importantes sobre os diversos métodos de análise existentes, contribuindo inclusive para novas propostas de classificação de terrenos tecnogênicos nos mapeamentos geológicos e geomorfológicos, assim como no âmbito da análise faciológica dos seus materiais deposicionais (PELOGGIA, 2017; PELOGGIA, 2018).

A estrutura de classificação e mapeamento de terrenos tecnogênicos apresentada em Peloggia et al. (2014) e Peloggia $(2017 ;$ 2018) se destaca, neste cenário, por abranger, de modo intuitivo, um amplo espectro de possibilidades de terrenos tecnogênicos, agrupados em quatro classes principais de terrenos: de agradação; modificado; de degradação; e complexo. Esta classificação, no entanto, não se aplica às construções incorporadas aos terrenos (tais como edificações e equipamentos urbanos), que afetam fortemente os processos geomorfológicos e se configuram como um importante desafio conceitual e operacional neste tipo de abordagem.

Para o registro e a interpretação dos depósitos sedimentares tecnogênicos, a classificação composicional e genética também constitui uma ferramenta relevante. Neste sentido, a classificação de fácies em camadas tecnogênicas, como exposto em Peloggia (2017) possibilita reconhecer, na identificação da composição do depósito, os diferentes materiais constituintes, como pode ser evidenciado nos tipos: úrbico (materiais terrosos em fragmentos, entulhos e detritos urbanos); gárbico (material detrítico com quantidade significativa de lixo orgânico); espólico (material proveniente da escavação do manto de intemperismo, eventualmente com material rochoso subordinado); sedimentar (material sedimentar indiferenciado, frequentemente com clastos tecnogênicos de granulação variada, e eventualmente tecnofósseis); e lítico (material rochoso de granulação diversa, eventualmente com material terroso subordinado).

Informações desta natureza são fundamentais para evitar o "encobertamento" das atividades humanas (e seus produtos) que precederam as atuais funções e formas dos terrenos. Não raramente, esta perda de memória gera tragédias, como a que ocorreu no Morro do Bumba, em Niterói, no ano de 2010, quando um grande movimento gravitacional de massa afetou um terreno 
ocupado por uma comunidade de baixa renda, terreno este formado pelos depósitos de um antigo lixão (REZENDE, 2016).

Pode-se dizer, pelo exposto, que os terrenos tecnogênicos configuram os produtos materiais dos processos antropogeomorfológicos (ou da geotecnogênese), e que não é possível estudar uns sem os outros. Os estudos apresentados demonstram que as formas de relevo tecnogênicas podem ser incorporadas aos procedimentos de mapeamento geomorfológico, e sua classificação aplicada ao ambiente fluvial, permitindo, assim, reconhecer as modificações nas características e comportamentos dos rios ou canais fluviais. Destaca-se ainda, a possibilidade de existência de terrenos tecnogênicos exclusivos aos ambientes fluviais.

\section{3) Geomorfologia Fluvial em ambientes urbanos: algumas abordagens}

Desde as últimas décadas do século XX, diversos projetos vêm surgindo, no contexto internacional, em busca de soluções para problemas ambientais relacionados aos rios. De um enfoque, inicialmente, sobre o saneamento de rios (como foi o caso do Tâmisa, do Sena e do Missisipi), objetivando alcançar melhores condições de qualidade da água, observamos, posteriormente, que os projetos passam para uma busca de reinserção dos rios na paisagem urbana, de recuperação da "memória" destes elementos, de conexão com espaços públicos, valorização de serviços ambientais prestados, e consideração efetiva da participação pública (SILVA-SÁNCHEZ; JACOBI, 2012). Iniciativas para a requalificação de rios, em um sentido mais amplo, foram impulsionadas, por exemplo, nos Estados Unidos, através da River Revitalization Foundation, no final dos anos 1980, e, na Europa, através do European Centre for River Restoration (ECRR), no final dos anos 1990. No ano 2000, a União Europeia adotou o EU Water Framework Directive, com o objetivo de alcançar boas condições ecológicas para os recursos hídricos superficiais e subterrâneos para todos os membros do bloco. No que se refere aos rios, os países deveriam elaborar mapas compreensíveis de condições ecológicas e químicas, incluindo a condição hidromorfológica (KONDOLF et al., 2016).

Esta nova mentalidade levou ao surgimento de inúmeros projetos de restauração fluvial e estudos voltados para esta temática, nos quais questões pertinentes à geomorfologia e aos habitats fluviais se tornaram cruciais (e.g. BRIERLEY; FRYIRS, 2000; FRYIRS; BRIERLEY, 2001; PALMER et al., 2005; SCORPIO et al., 2015). Concomitantemente, surgiram diferentes metodologias de classificação de canais fluviais, baseadas em relações entre processos e formas evidenciadas nas pesquisas realizadas, que se associam diretamente aos elementos geomorfológicos dos ambientes fluviais, visando dar suporte a estas novas abordagens nos projetos de restauração fluvial (ROSGEN, 1994; MONTGOMERY; BUFFINGTON, 1997; BRIERLEY; FRYIRS, 2000; 2005; BEECHIE; IMAKI, 2014; etc.). Nestas abordagens, tem sido destacada a necessidade de: (1) reconhecer as características e o comportamento dos cursos fluviais, antes de se efetuar avaliações das condições e do potencial de recuperação dos mesmos; e (2) dar enfoque nas análises de descontinuidades e controles locais que produzem heterogeneidades na paisagem, em contraponto a uma visão exclusiva de rede hidrográfica calcada na sua geometria e nas dimensões do sis- 
tema fluvial, presente em abordagens ligadas à modelagem hidrológica. A preocupação em sistematizar o levantamento de bases geomorfológicas, isto é, o mapeamento de elementos geomorfológicos ligados à dinâmica fluvial, através de estruturas taxonômicas consistentes, a fim de facilitar as etapas seguintes em um processo coerente de gestão de rios, também tem recebido crescente atenção em âmbito internacional (WYRICK; PASTERNACK, 2014; WYRICK et al., 2014; WHEATON et al., 2015; GURNELL et al., 2016; BELLETI et al., 2017).

Recentemente, constata-se que algumas destas metodologias de classificação de canais fluviais ou de mapeamento das feições geomorfológicas fluviais vêm incorporando elementos da paisagem urbana em seus procedimentos. Com o objetivo de construir uma taxonomia das feições geomorfológicas fluviais, Wheaton et al. (2015), por exemplo, inserem variáveis antropogênicas nas definições das margens fluviais e dos elementos estruturais do rio. Segundo estes autores, todas as margens fluviais, sejam elas de canal (channel margin), de fundo de vale (valley bottom margin) ou de vale (valley margin) podem, se for o caso, ser classificadas como antropogênicas, e tipificadas em margens de aterro, cerca (que pode ser constituída também por plantas ou arbustos), dique construído, ferrovia, rodovia e muro.

A definição das margens fluviais é importante para a interpretação da dinâmica fluvial, pois a partir delas pode se atribuir o grau de confinamento de um rio em relação ao vale em que está inserido (sendo este grau de confinamento reconhecido, em geral, pelos tipos confinado, parcialmente confinado ou não confinado). No caso das margens antropogênicas, observa-se que com frequência geram aumento do grau de confinamento de um rio. Em um rio meandrante, por exemplo, que é característico de vales não confinados e tem um comportamento típico de erodir as margens côncavas e depositar sedimentos nas margens convexas (formando a barra em pontal), realizando assim uma movimentação lateral ao longo da planície fluvial, a inserção de margens antropogênicas pode impedir ou dificultar significativamente o movimento lateral do canal fluvial, que passaria a ter um comportamento de canal confinado

Outro importante destaque vem sendo dado aos elementos estruturais, que segundo Wheaton et al. (2015) constituem objetos discretos que exercem influência na estrutura (configuração) dos canais, por afetarem a hidráulica do rio. Sua presença é uma indicação direta do grau de complexidade estrutural ou heterogeneidade dos rios. Alguns exemplos de elementos estruturais de origem antropogênica são: revestimento de margens; pilares de pontes; bueiros; e grandes detritos residuais de madeira de obras de engenharia, dentre outros.

Avanços recentes na metodologia dos Estilos Fluviais (BRIERLEY; FRYIRS, 2000; 2005) incluem procedimentos para a análise e classificação de rios antropogenicamente modificados e urbanos (FRYIRS; BRIERLEY, 2018), a partir dos mesmos pressupostos de confinamento antropogênico de vale encontrados em Wheaton et al. (2015). Desta maneira, Fryirs e Brieley (2018) identificam diferentes tipos de margens antropogênicas, tais como diques construídos, aterros, revestimento de margens, rodovias, ferrovias, dentre outras, incorporando as modificações antropogênicas ocorridas no vale fluvial.

$\mathrm{Na}$ União Europeia, sob o contexto da EU Water Framework Directive anteriormente mencionada, destaca-se o desenvolvimento de uma estrutura de classificação hierárquica multiescalar - muito influenciada pela metodologia de Brierley e Fryirs (2005) - denominada REFORM (REstoring rivers FOR effective catchment Management), com o objetivo de auxiliar a gestão de 
rios (GURNELL et al., 2016; RINALDI et al., 2016). Apesar dos méritos e bons resultados da adoção da estrutura de classificação REFORM, ainda se nota um tratamento 'tímido' dos ambientes intensamente modificados (como os urbanos), limitando-se à identificação de canais fluviais e materiais de leito artificiais (RINALDI et al., 2016).

No Brasil, embora haja diversos estudos sobre as modificações antropogênicas em bacias hidrográficas, inclusive com mapeamento dos terrenos tecnogênicos (e.g. PELOGGIA et al., 2018) e trechos de rio retificados (e.g. ASSUMPÇÃO; MARÇAL, 2012; LIMA; MARÇAL, 2013, dentre outros), ainda há carência de investigações sobre as características e o comportamento dos rios urbanos.

\section{4) Rios urbanos brasileiros: cenário, exemplos e questões}

No contexto brasileiro, percebe-se que o tratamento dado aos rios, em geral, não parece acompanhar as mesmas fases e as grandes mudanças do pensamento ambiental do final do século XX e início do século XXI, que promoveram, inicialmente, o saneamento e o tratamento das águas das áreas urbanas e, posteriormente, um movimento em direção à restauração fluvial ${ }^{1}$. A Pesquisa Nacional de Saneamento Básico (IBGE, 2010) mostra que apenas 55\% dos municípios brasileiros possuem serviço de esgotamento sanitário por rede coletora e, deste montante, apenas 50\% possuem tratamento de esgoto, indicando uma grande distância da realidade brasileira em relação às condições de saneamento de muitos países desenvolvidos, não obstante a reconhecida diversidade de condições de desigualdade ambiental e social nestes países.

Ademais, permanece, no Brasil, de modo mais ou menos generalizado, uma lógica calcada na percepção do rio apenas como escoadouro de águas. Ao longo do século XX, por exemplo, diversas ações de canalização, impermeabilização, retificação e alargamento de canais fluviais executadas por órgãos de governo tiveram por objetivo drenar as planícies de inundação, controlar as enchentes, evitar a proliferação da malária e aumentar a extensão de terras secas para estimular as atividades agropecuárias, assim como a instalação de assentamentos urbanos e plantas industriais (OLIVEIRA et al., 2006; ASSUMPÇÃO; MARÇAL, 2012; BRENNER, 2016; dentre outros). Além disso, as condições altamente degradadas de muitos rios urbanos, conjugadas a políticas ambientais ineficientes, à exclusão social e injustiça ambiental, aos entraves à participação das organizações sociais e coletivos na gestão das cidades, e também à falta de conhecimentos sobre a memória e os ambientes das cidades (e seus entornos), têm levado a um processo de invisibilização dos rios, muitas vezes refletido na adoção de termos associados a ambientes construídos degradados, como por exemplo o 'valão' (FERREIRA, 1998; CAMELO et al., 2014; NETTO et al. 2019).

É perceptível, assim, que as planícies fluviais dos rios urbanos brasileiros sofreram e ainda sofrem fortes impactos do intenso processo de ocupação, que em geral desconsideram as carac-

\footnotetext{
${ }^{1}$ É importante ressaltar que o termo 'restauração' vem sendo utilizado no texto em um sentido abrangente, com o propósito de abarcar, tentativamente, uma ampla variedade de concepções e métodos envolvidos na recuperação, renaturalização e reabilitação fluviais, cujas diferenciações de objetivos, concepções e métodos, apesar de reconhecidas, não constituem o foco de análise do presente artigo.
} 
terísticas e os comportamentos dos canais fluviais, assim como as funções ecológicas e sociais que eles exercem ou exerceriam (potencialmente). Estes aspectos podem ser observados na figura 2, em que são visualizados alguns trechos de rios urbanos brasileiros intensamente modificados.

Na Figura 2A, observa-se um trecho do rio Tietê na cidade de São Paulo, evidenciando características de rio canalizado e retificado, e atualmente inteiramente confinado por margens antropogênicas constituídas por muros e rodovias, com planícies totalmente ocupadas pela malha urbana. Rodrigues et al. (2019) apontam que os últimos cem anos de crescimento da cidade de São Paulo resultaram na alta magnitude de transformações na bacia hidrográfica do Alto Tietê, com algumas taxas de mudanças equivalentes às de eventos tectônicos catastróficos. Também com características de rio canalizado retificado e confinado por margens antropogênicas, observamos na Figura 2B o Igarapé do Franco, afluente do Igarapé São Raimundo, estando este último, ainda que sob forte pressão da ocupação urbana, com presença de margens vegetadas e sem edificações em alguns locais. Costa Júnior e Nogueira (2011) constatam que, desde o final do século XIX, as intervenções urbanas realizadas nos igarapés de Manaus se basearam na remoção da população ribeirinha, na canalização e no aterramento das margens, seguindo o 'modelo' adotado nas obras públicas no Brasil. Segundo estes autores, as recentes intervenções (século XXI) têm apresentado, por outro lado, apenas uma preocupação estética, não funcional. 

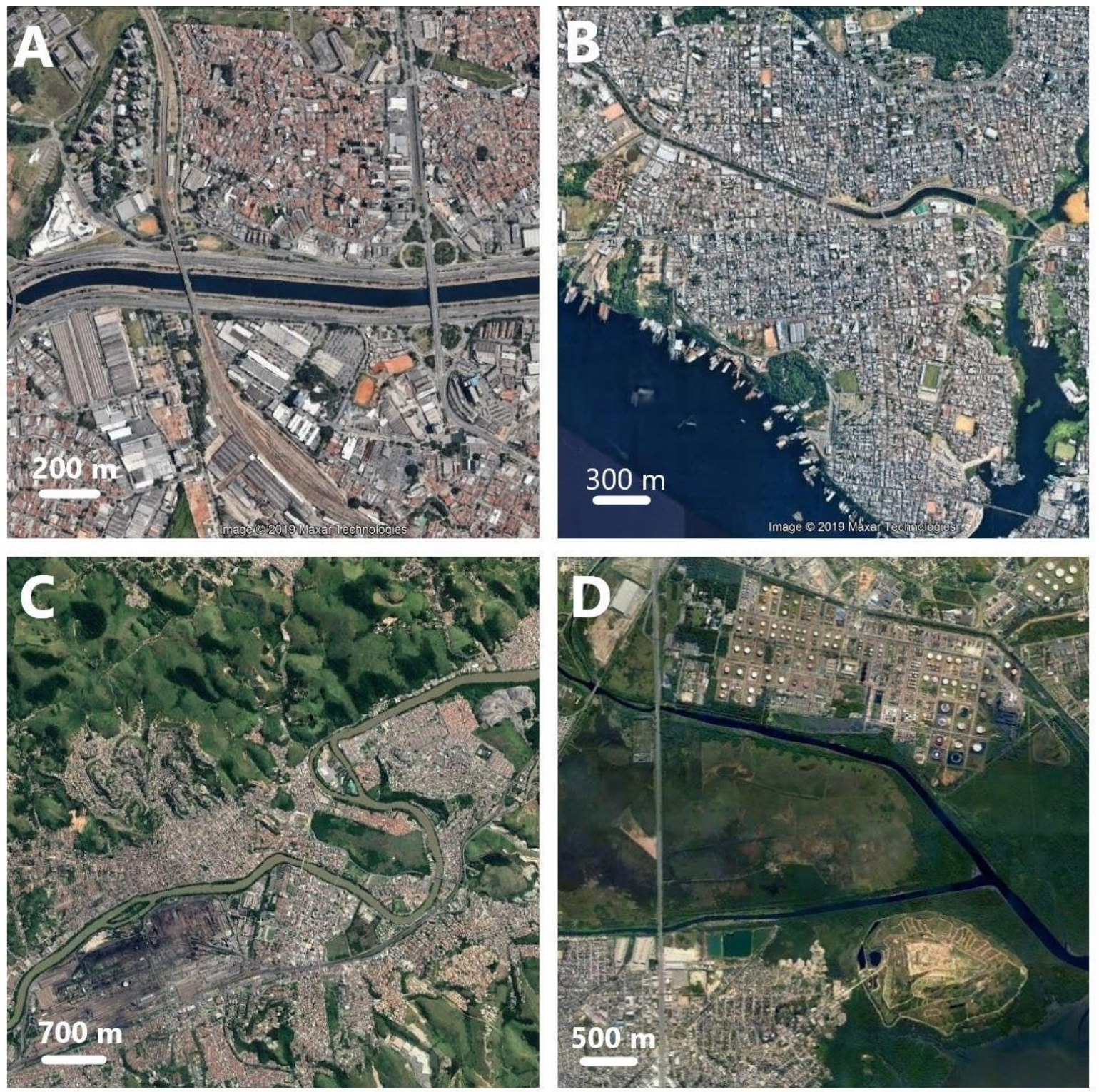

Figura 2. Exemplos de rios urbanos brasileiros intensamente modificados. A: rio Tietê (sentido do fluxo para esquerda), localizado na cidade de São Paulo; B: Igarapé do Franco (parte superior da imagem) e Igarapé São Raimundo (à direita), atravessando a cidade de Manaus (rio Negro no trecho inferior da imagem); C: rio Paraíba do Sul (sentido do fluxo para direita) na cidade de Volta Redonda, RJ D: rio Sarapuí (parte inferior) e rio Iguaçu (parte superior) na Baixada Fluminense, Região Metropo-litana do Rio de Janeiro (notar o Aterro Controlado de Jardim Gramacho na parte inferior, à direita, nesta imagem). Fonte das imagens de satélite: Google Earth.

Já no trecho do rio Paraíba do Sul (Figura 2C), que atravessa a cidade de Volta Redonda (RJ), observa-se a manutenção de grande parte do seu traçado anterior à implantação da cidade, que apresenta forte controle estrutural e neotectônico (NEGRÃO et al., 2015), porém, devido à densa ocupação da planície de inundação, também se configura como um rio confinado por margens antropogênicas. Em contexto das amplas planícies da Baixada Fluminense, por fim, obser- 
vamos os rios Sarapuí e Iguaçu (Figura 2D), na Região Metropolitana do Rio de Janeiro, apresentando leitos canalizados e retificados predominantemente confinados por margens antropogênicas. Estes, conforme avançam em direção aos manguezais e à Baía da Guanabara, onde deságuam, passam a exibir trechos não confinados, porém ainda com seus traçados modificados. Chama a atenção a presença, nesta última imagem, a presença, em área de grande sensibilidade ambiental, do Aterro Controlado de Jardim Gramacho, um terreno tecnogênico de agradação que recebeu os resíduos de diversas áreas da Região Metropolitana do Rio de Janeiro por décadas, sem controle adequado. Segundo Damasco e Cunha (2014), muitas das canalizações e retificações de rios realizadas no século XX na Região Metropolitana do Rio de Janeiro tiveram como objetivo a destinação de áreas para loteamentos.

É difícil imaginar a execução com sucesso de projetos de restauração fluvial em ambientes urbanos intensamente modificados e de ocupação já consolidada, como a situação observada na Figura 3, por envolverem intervenções complexas e de alto custo. Contudo, há exemplos exitosos de restauração de ambientes fluviais degradados, como o famoso caso do rio Cheonggyecheon em Seul na Coréia do Sul (Figura 4), que foi recuperado e refuncionalizado, sendo muito destacada a intensificação da interação da população urbana com o rio, além da criação de uma atração com forte apelo turístico, com aproximadamente 90 mil pedestres percorrendo-o diariamente (MAYER, 2012).

Conforme Brierley e Fryirs (2005), um rio urbano intensamente modificado, como boa parte dos rios urbanos brasileiros, de maneira geral, seria tipificado como em situação precária em relação às condições geomorfológicas e ecológicas e, devido à sua localização em áreas urbanas consolidadas, teria baixo potencial de restauração. Logo, para estes casos, a refuncionalização social dos rios, associada a projetos de reabilitação geomorfológica e ecológica, configuram-se como possibilidades interessantes para implementação, considerando-se as expectativas dos moradores e usuários das cidades.

Nesse sentido, Brocaneli e Stuermer (2008) e Silva-Sánchez e Jacobi (2012) relatam, ao analisar a gestão ambiental na cidade de São Paulo, que as soluções mais voltadas a uma perspectiva ecológica ainda são raras e difíceis de serem executadas. Iniciativas potencialmente promissoras, como os Programas de Canalização de Córregos, Implantação de Vias e Recuperação Ambiental e Social dos Fundos de Vale (PROCAV 1 e PROCAV 2), se limitaram, no que se refere às intervenções no ambiente fluvial, a canalizar rios e córregos, além de construir reservatórios do tipo "piscinão". 


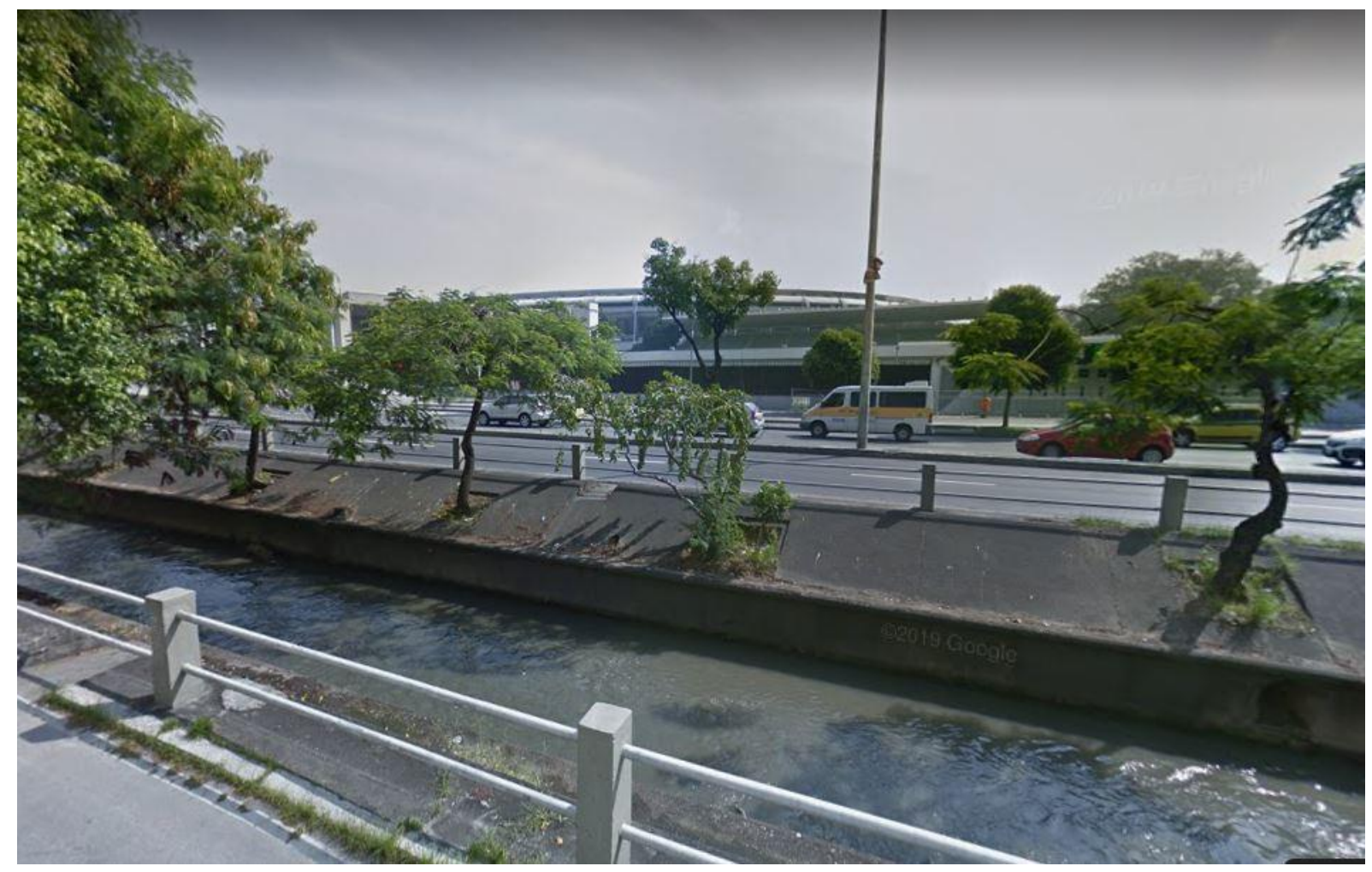

Figura 3. Rio Maracanã, localizado na cidade do Rio de Janeiro. Observa-se a canalização do rio, que está confinado por margens antropogênicas e recebe uma grande carga de esgoto sem tratamento e resíduos sólidos, com vias de grande fluxo instaladas na sua planície. Ao fundo, o estádio de futebol homônimo. Fonte: Google Maps (maio de 2017).

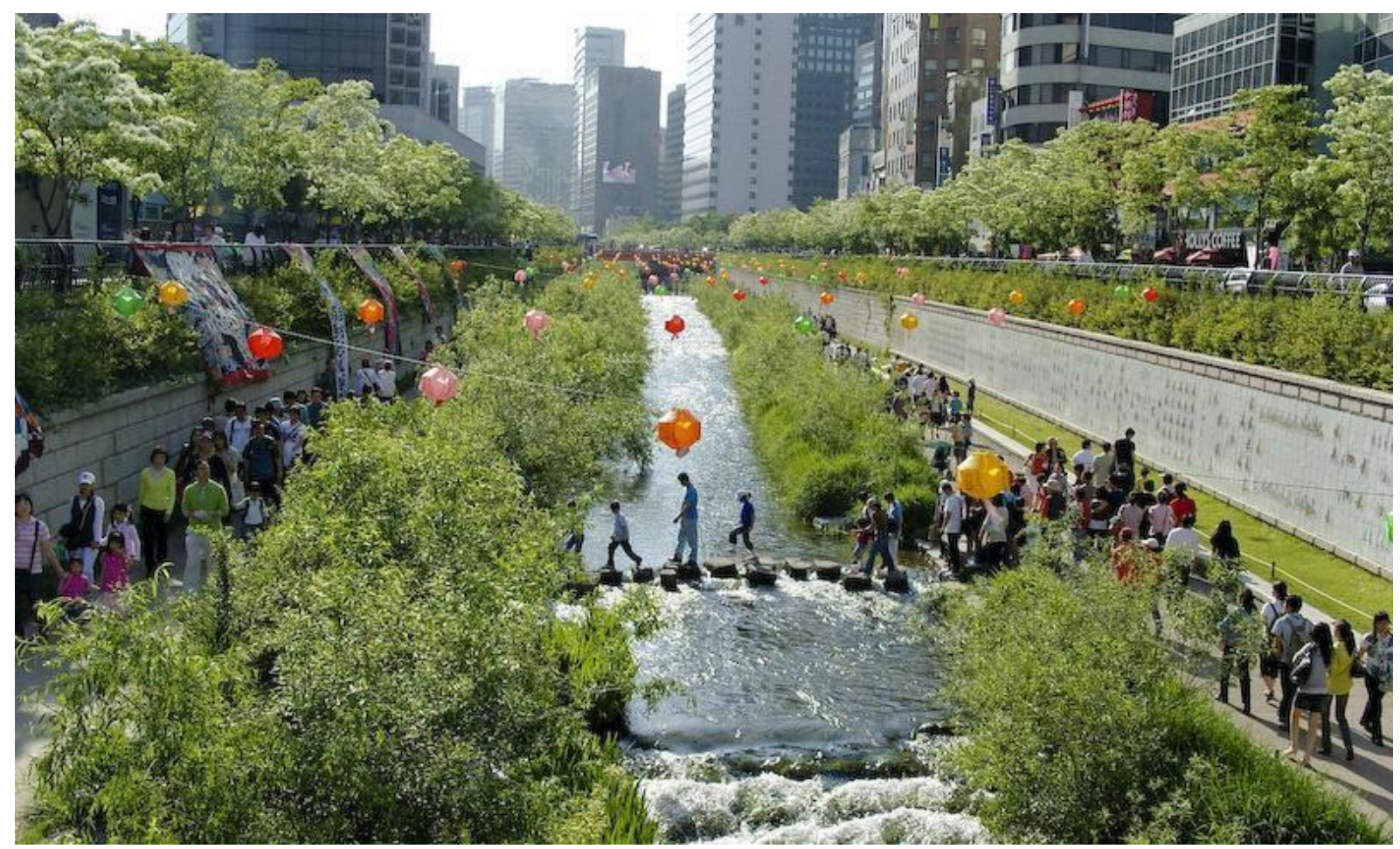

Figura 4. Trecho revitalizado do rio Cheonggyecheon em Seul, na Coréia do Sul. Fonte: Wikipedia (https://en.wikipedia.org/wiki/File:Korea-Seoul-Cheonggyecheon-2008-01.jpg\#filelinks). 
Apesar dos desafios inerentes, existem diversas oportunidades para a implantação de projetos de restauração e/ou refuncionalização de rios sob novas perspectivas, no Brasil. Recentemente, uma obra de 'revitalização' do rio Icaraí, na cidade de Niterói (RJ), promoveu o desvio da entrada de esgoto e a diminuição do fluxo de água no trecho em que o rio atravessa a área verde do Campo de São Bento (um parque municipal) para evitar o odor das águas no local. A Secretaria Municipal de Conservação e Serviços Públicos, à época, argumentou que com a diminuição do fluxo de água seria possível concretar o fundo do canal, o que, na visão exposta, auxiliaria na sua manutenção (Figura 5). Certamente perdeu-se ali uma oportunidade de iniciar um processo de refuncionalização real do rio, através da restauração de aspectos geomorfológicos e ecológicos e da ressignificação do rio para a sociedade, tal qual observamos no exemplo sul-coreano, citado anteriormente.

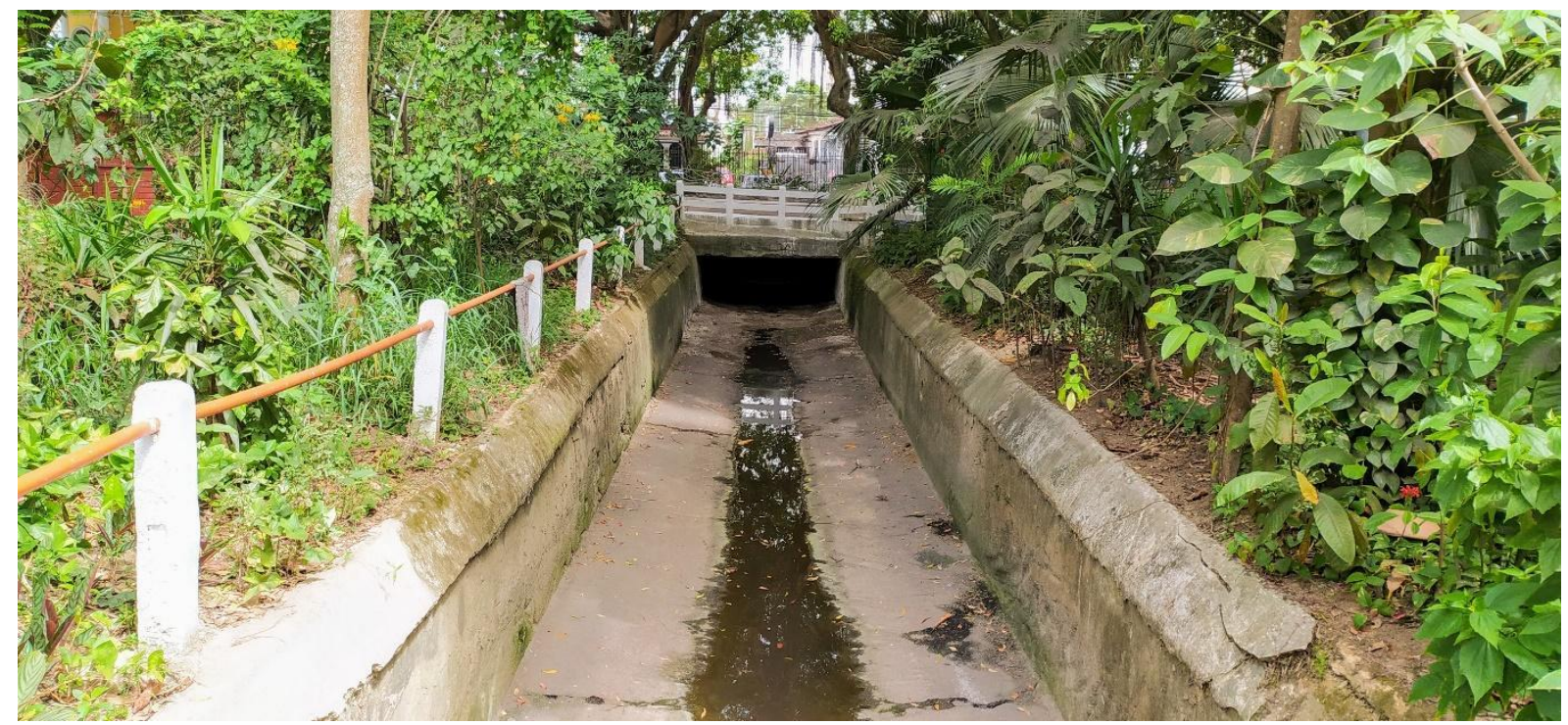

Figura 5. Rio Icaraí, localizado na cidade de Niterói (RJ), no trecho em que atravessa a área verde do Campo de São Bento. A intervenção promovida pela prefeitura resultou na redução do fluxo de água em um trecho já canalizado e concretado em suas margens e leito. Foto: André Pelech (dezembro de 2019).

No ambiente urbano, as planícies fluviais com baixa densidade de ocupação e as áreas verdes podem se configurar como locais estratégicos para os projetos de restauração fluvial, pois geralmente apresentam maior facilidade para execução de intervenções para esse fim, tendo em vista que não necessitam de remoções ou grandes investimentos de recursos materiais. É de fundamental importância que estes projetos potencializem as funções sociais dos rios, permitindo que a sociedade local os reconheça, a eles se (re)conectem, os valorizem e protejam. Para isto, é também necessária atenção especial aos processos de ocupação ligados ao crescimento urbano acelerado nas grandes metrópoles brasileiras, visto que a desigualdade social, nas cidades, está notadamente imbricada com a desigualdade ambiental, isto é, grupos sociais vulnerabilizados estão sujeitos a condições de maior risco. No caso dos ambientes fluviais, isto significa uma maior exposição aos impactos dos eventos de inundação (e.g. TORRES, 1997; ALVES, 2007), à contaminação por efluentes dispostos nos corpos hídricos (e.g. OLIVEIRA et al., 2015) e às doenças 
de veiculação hídrica, dentre outros. Assim, todo o processo de (re)conexão com os rios passa, necessariamente, pelo enfrentamento das desigualdades.

\section{5) "Retrato geomorfológico" dos rios urbanos}

Não se pretende aqui apresentar uma metodologia específica para o reconhecimento geomorfológico de rios urbanos, mas, à luz dos conceitos da Antropogeomorfologia, dos estudos sobre os terrenos tecnogênicos e das classificações de feições fluviais, sugerir alguns procedimentos que permitam avaliar características e funcionamentos dos rios inseridos em realidades urbanas diversas, tendo em vista que a tipologia fluvial, isto é, a classificação geomorfológica de rios, vem se mostrando bastante útil para aplicação na gestão ambiental. Assim, construir um "retrato geomorfológico" pode servir de subsídio para projetos de restauração e/ou de refuncionalização de rios, dentro da perspectiva discutida.

Deste modo, apresentamos etapas consideradas importantes na identificação e classificação de elementos da paisagem fluvial (Figura 6). A primeira etapa consiste no mapeamento de feições geomorfológicas fluviais, as quais, nos estudos de língua inglesa, são frequentemente denominadas de geomorphic units ou channel units. Segundo Wheaton et al. (2015), uma feição geomorfológica fluvial (ou unidade geomorfológica) é uma feição (forma de relevo) que constitui um subproduto dos processos de erosão e sedimentação. Estas feições funcionam como 'peças' na construção da estrutura dos rios, representando uma associação específica de formas e processos geomorfológicos (FRYIRS; BRIERLEY, 2013). Metodologias de organização destas peças estruturantes, como a taxonomia das formas fluviais proposta por Wheaton et al. (2015), que incorpora elementos antropogênicos, podem ser utilizadas nesta etapa.

A segunda etapa sugerida consiste na identificação daquelas feições de caráter tecnogênico, isto é, construídas pela ação técnica humana. Planícies, barras, rápidos, margens, dentre outras feições geomorfológicas fluviais, podem ser identificados como tecnogênicos nesta etapa. Metodologias de classificação de feições tecnogênicas, como a proposta por Peloggia (2017; 2018), são recomendadas.

A terceira e última etapa consiste na identificação do tipo de rio, com base no que foi identificado e analisado nas etapas anteriores. Na literatura internacional figuram inúmeras classificações geomorfológicas de rios baseadas nas assembleias de feições geomorfológicas encontradas em trechos de canal, trechos estes reconhecidos pelas suas características homogêneas (e.g. FRISSEL et al., 1986; ROSGEN, 1994; MONTGOMERY; BUFFINGTON, 1997; BRIERLEY; FRYIRS, 2000; 2005). A utilização de uma tipologia fluvial aberta, que permita a incorporação de elementos antropogênicos, é desejável, sendo um bom exemplo a de Fryirs e Brierley (2018), elaborada com base em estudos realizados em diversos países, com destaque para os apresentados em Brierley e Fryirs (2000; 2005).

As metodologias sugeridas buscam amparar, de modo organizado, o reconhecimento geomorfológico de rios urbanos incorporando os elementos antropogênicos. Contudo, ainda são necessários estudos para melhor caracterizar as formas antropogênicas do ambiente fluvial. Com frequência os rios urbanos apresentam margens com as mais diversas características, como mu- 
ros de concreto, muros de pedra, árvores, solos com cobertura de gramíneas, dentre outras. O leito fluvial também pode se apresentar com características análogas às das condições naturais, quando constituído de material sedimentar ou rochoso, ou ainda com características novas, artificiais, quando há impermeabilização por revestimentos de concreto, por exemplo. Além disso, o estado de conservação das estruturas de engenharia pode variar bastante, apresentando-se, por vezes, em processo de erosão avançada. Deste modo, a identificação das características e comportamentos dos diferentes tipos de margens e de leito fluviais frente aos processos hidrológicos e geomorfológicos parece trazer questões profícuas para os futuros estudos a serem realizados dentro desta temática.

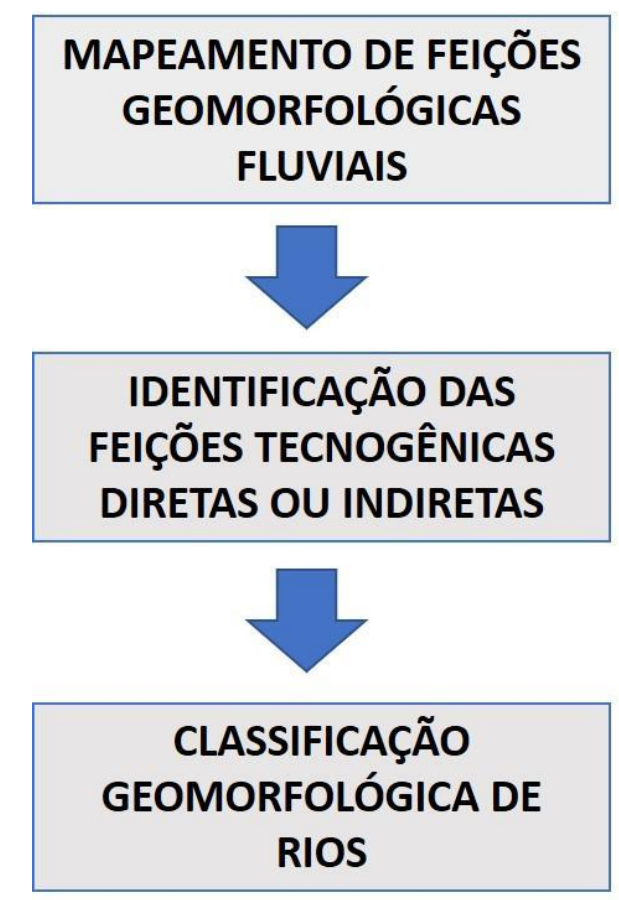

Figura 6. Etapas para a construção de um 'retrato geomorfológico' dos rios urbanos. A identificação e classificação de elementos da paisagem fluvial busca avaliar características e funcionamento dos rios em diferentes contextos urbanos para aplicação na gestão ambiental..

\section{Considerações finais}

A Antropogeomorfologia e os estudos sobre os terrenos tecnogênicos mostram-se fundamentais para a compreensão da dinâmica fluvial em ambientes intensamente modificados e controlados pelas atividades humanas, onde as ferramentas utilizadas usualmente não se mostram suficientes para compreender a dinâmica das paisagens. Diferente dos ambientes rurais antropizados, onde os processos geomorfológicos guardam uma dinâmica ainda fortemente associada a controles naturais, em diferentes escalas, os rios das áreas urbanas apresentam processos e formas ligados diretamente às intervenções e ao modo como são apropriados pela sociedade. 
As pesquisas voltadas para classificação de rios e o mapeamento de feições geomorfológicas fluviais têm, cada vez mais, incorporado elementos antropogênicos em seus arcabouços metodológicos. O reconhecimento de terrenos tecnogênicos e de seus controles sobre a dinâmica fluvial é promissor para o estudo de rios urbanos, abrindo espaço para pesquisas voltadas à elaboração de uma tipologia de rios que envolva o entendimento da função das margens antropogênicas no condicionamento do rio e o reconhecimento dos materiais, formas e processos do leito, das margens e da planície fluvial.

Em paisagens profundamente modificadas pela ação humana, é fundamental desenvolver métodos que possibilitem reconhecer os terrenos tecnogênicos como resultantes e condicionantes diretos e indiretos das ações das sociedades. Assim, tal como é necessário considerar o fluxo, a declividade e os suprimentos de água e sedimentos como fatores que condicionam as características e o funcionamento dos rios, deve-se ter em mente que as ações humanas configuram-se como um fundamental construtor de processos e formas, controles e efeitos na dinâmica de transformações dos ambientes urbanos. Neste sentido, é importante compreender as dinâmicas políticas e sociais que se associam à modificação física das paisagens, como destacado nas abordagens da Geografia Física Crítica (e.g. LAVE et al., 2018) e da Geografia Ambiental (e.g. SOUZA, 2019). É preciso reconhecer que os processos e as formas dos ambientes fluviais não podem mais ser explicados apenas por variáveis ditas naturais. Nessa perspectiva, é plausível considerar os rios como sistemas socioecológicos (PARSONS et al., 2016).

A gestão ambiental de rios urbanos brasileiros constitui um enorme desafio, pois além de terem sofrido diversas intervenções que modificaram seus leitos, margens e planícies, ainda sofrem os efeitos dos péssimos serviços de esgotamento sanitário e de tratamento de esgotos, em um contexto de várias outras condições de exclusão e (in)justiça social e ambiental. Contudo, as demandas ambientais do século XXI necessitam de respostas que resultem em mudanças de paradigma. No que se refere aos rios urbanos brasileiros (ou àqueles profundamente modificados em outros contextos) e considerando-se a produção científica nas áreas aqui discutidas, algumas medidas urgentes se mostram necessárias para a mudança apontada: (1) a adoção e difusão das classificações geomorfológicas de rios em estudos científicos e projetos de restauração fluvial; (2) a incorporação efetiva das formas e terrenos tecnogênicos nos sistemas de classificação geomorfológica; e (3) a articulação com as dinâmicas sociais e o caráter político das ações que visam os interesses e direitos coletivos.

Nesse sentido, buscar modos de integração entre as abordagens geomorfológicas e estudos socioeconômicos e socioculturais, bem como com as ciências da vida, torna-se necessidade fundamental à medida em que caminhamos para o Antropoceno (LARGE et al., 2018). Projetos, iniciativas e políticas voltadas aos rios urbanos devem abranger, além de um profundo conhecimento dos seus componentes e dinâmicas, a refuncionalização e ressignificação social dos rios, para que a sociedade não apenas os valorize e proteja, mas se (re)conheça na (con)vivência com os rios. 
Os autores agradecem ao Instituto Brasileiro de Geografia e Estatística (IBGE) e ao NEQUAT-IGEO/UFRJ pelo suporte institucional e financeiro na realização desta pesquisa. Agradecemos também aos revisores por suas críticas e sugestões que contribuíram significativamente para a melhoria do artigo.

Submetido em 4 de junho de 2020. Aceito para publicação em 8 de setembro de 2020.

\section{Referências}

ALVES, H. P. F. Desigualdade ambiental no município de São Paulo: análise da exposição diferenciada de grupos sociais a situações de risco ambiental através do uso de metodologias de geoprocessamento. Revista Brasileira de Estudos de População, v. 24, n. 2, p. 301316, 2007.

ASSUMPÇÃO, A. P.; MARÇAL, M. S. Retificação dos canais fluviais e mudanças geomorfológicas na planície do rio Macaé (RJ). Revista de Geografia (UFPE), v. 29, n. 3, 2012.

BEECHIE, T.; IMAKI, H. Predicting natural channel patterns based on landscape and geomorphic controls in the Columbia River basin, USA. Water Resources Research, v. 50, p. 39-57, 2014.

BELLETI, B.; RINALDI, M.; BUSSETINI, M.; COMITI, F.; GURNELL, A. M.; MAO, L.; NARDI, L.; VEZZA, P. Characterising physical habitats and fluvial hydromorphology: A new system for the survey and classification of river geomorphic units. Geomorphology, v. 283, p. 143-157, 2017.

BOTELHO, R. G. M. Bacias hidrográficas urbanas. In: GUERRA, A. J. T. (org). Geomorfologia Urbana. Rio de Janeiro: Bertrand Brasil, p. 71-115, 2011.

BRENNER, V. C. Proposta metodológica para renaturalização de trecho retificado do rio Gravataí. 2016. 94 f. Dissertação (Mestrado em Geografia) - POSGEA/UFRGS, Porto Alegre, 2016.

BRIERLEY, G. J.; FRYIRS, K. River Styles, a Geomorphic Approach to Catchment Characterization: Implications for River Rehabilitation in Bega Catchment, New South Wales, Australia. Environmental Management, v. 25, n. 6, p. 661-679, 2000. 
BRIERLEY, G. J.; FRYIRS, K. A. Geomorphology and River Management: Applications of the River Styles Framework. Blackwell Publishing, 2005. 398 p.

BROCANELI, P. F.; STUERMER, M. M. Renaturalização de rios e córregos no município de São Paulo. Exacta, v. 6, n. 1, p. 147-156, 2018.

CAMELO, T. R.; SOUSA, L. G. S.; OLIVEIRA, P. A. R.; MATTOS, B. S. E aí fessor@, desde quando valão é rio? Córregos urbanos e bacias hidrográficas: concepções de alunos do ensino fundamental de uma escola pública no município de São Gonçalo, RJ. Anais do VII Congresso Brasileiro de Geógrafos, 2014. Vitória, 2014. 10 p. Disponível em: <http://www.cbg2014.agb.org.br/resources/anais/1/1404607707 ARQUIVO TrabalhoCBG 1 .pdf>. Acesso em: 15 set. 2020.

COSTA JÚNIOR, W. R.; NOGUEIRA, A. R. B. A requalificação ambiental do igarapés de Manaus (2005-2008): um contínuum das políticas de urbanização do século XIX?. Cad. Pesq. Cdhis, v. 24, n. 1, p. 105-123, 2011.

CRUTZEN, P.J.; STOERMER, E.F. The "Anthropocene”. IGBP Newsletter v. 41, p. 17-18, 2000.

DAMASCO, F. S.; CUNHA, S. B. Reconstituição das alterações em canais fluviais urbanizados com base na cartografia histórica: bacia dos rios Guaxindiba/Alcântara (RJ). Revista Geonorte, v.10, n. 1, p. 446-452, 2014.

FERREIRA, J. Cuidados do Corpo em Vila de Classe Popular. In: DUARTE, L. F. D.; LEAL, O. F. (orgs). Doença, Sofrimento, Perturbação: perspectivas etnográficas. Rio de Janeiro: FIOCRUZ, p 47-56, 1998.

FRISSELL, C. A.; LISS, W. J.; WARREN, C. E.; HURLEY, M. D. A Hierarchical Framework for Stream Habitat Classification: Viewing Streams in a Watershed Context. Environmental Management, v. 10, n. 2, p. 199-214, 1986.

FRYIRS, K.; BRIERLEY, G. J. Variability in sediment delivery and storage along river courses in Bega catchment, NSW, Australia: implications for geomorphic river recovery. Geomorphology, v. 38, p. 237-265, 2001.

FRYIRS, K. A.; BRIERLEY, G. J. What's in a name? A naming convention for geomorphic river types using the River Styles Framework. PLoS ONE, v. 13, n. 9, 2018. Doi: <https://doi.org/10.1371/journal.pone.0201909>.

GIBLING, M. R. River Systems and the Anthropocene: A Late Pleistocene and Holocene Timeline for Human Influence. Quaternary, v. 1, n. 3, 21, 2018.

GOUDIE, A.; VILES, H. A. Geomorphology in the Anthropocene. Cambridge University Press, 2016.

GURNELL, A.; LEE, M.; SOUCH, C. Urban Rivers: Hydrology, Geomorphology, Ecology and Opportunities for Change. Geography Compass, v. 1, n.5, p. 1118-1137, 2007.

GURNELL, A. M.; RINALDI, M.; BELLETI, B.; BIZZI, S.; BLAMAUER, B.; BRACA, G.; BUIJSE, A. D.; BUSSETINI, M.; CAMENEN, B.; COMITI, F.; DEMARCHI, L.; GARCÍA DE JALÓN, D.; GONZÁLEZ DEL TÁNAGO, M.; GRABOWSKI, R. C.; GUNN, I. D. M.; HABERSACK, H.; HENDRIKS, D.; HENSHAW, A. J.; KLÖSCH, M.; LASTORIA, B.; LATAPIE, A.; 
MARCINKOWSKI, P.; MARTÍNEZ-FERNÁNDEZ, V.; MOSSELMAN, E.; MOUNTFORD, J. O.; NARDI, L.; OKRUSZKO, T.; O'HARE, M. T.; PALMA, M.; PERCOPO, C.; SURIAN, N.; VAN DE BUND, W.; WEISSTEINER, C.; ZILIANI, L. A multi-scale hierarchical framework for developing understanding of river behaviour to support river management. Aquatic Sciences, v. 78, p. 1-16, 2016.

HUPY, J. P. Anthropogeomorphology. In: RICHARDSON, D.; CASTREE, N.; GOODCHILD, M. F.; KOBAYASHI, A.; LIU, W.; MARSTON, R. A. The International Encyclopedia of Geography. John Wiley \& Sons, Ltd, 2017. DOI: 10.1002/9781118786352.wbieg0664

IBGE. INSTITUTO BRASILEIRO DE GEOGRAFIA E ESTATíSTICA. Pesquisa Nacional de Saneamento Básico: 2008. IBGE, Coordenação de População e Indicadores Sociais, 2010.

IBGE. INSTITUTO BRASILEIRO DE GEOGRAFIA E ESTATÍSTICA. População por situação do domicílio, 1950 - 2010. Séries históricas (censos demográficos). Disponível em: <ibge.gov.br/estatisticas/sociais/habitacao/9662-censo-demografico-2010.html?=\&t=serieshistoricas>. Acesso em: 04 dez. 2019.

JAMES, L. A.; MARCUS, W. A. The human role in changing fluvial systems: Retrospect, inventory and prospect. Geomorphology, v. 79, p. 152-171, 2006.

JORGE, M. C. O. Geomorfologia Urbana: conceitos, metodologias e teorias. In: GUERRA, A. J. T. (org). Geomorfologia Urbana. Rio de Janeiro: Bertrand Brasil, p. 117-145, 2011.

KELLY, J. M. Anthropocenes: A Fractured Picture. In: KELLY, J. M.; SCARPINO, P. V.; BERRY, H.; SYVITSKI, J.; MEYBECK, M. (eds) Rivers of the Anthropocene. Oakland: University of California Press, p. 1-18, 2018. doi: https://doi.org/10.1525/luminos.43.

KONDOLF, G. M.; PIÉGAY, H.; SCHMITT, L.; MONTGOMERY, D. R. Geomorphic classification of rivers and streams. In: KONDOLF, G. M.; PIÉGAY, H. (editores). Tools in Fluvial Geomorphology, segunda edição, John Wiley \& Sons, Ltd, 2016. 568 p.

LARGE, A.; GILVEAR, D.; STARKEY, E. Ecosystem Service-Based Approaches for Status Assessment of Anthropocene Riverscapes. In: KELLY, J. M.; SCARPINO, P.; BERRY, H.; SYVITSKI, J.; MEYBECK, M. (eds). Rivers of the Anthropocene.Oakland: University of California, p. 23-42, 2018.

LAVE, R.; BIERMANN, C.; LANE, S. N. Introducing Critical Physical Geography. In: LAVE, R.; BIERMANN, C.; LANE, S. N. (editores) The Palgrave Handbook of Critical Physical Geography. Palgrave Macmillan, p. 3-20, 2018.

LAVE, R.; WILSON, M. W.; BARRON, E. S.; BIERMANN, C.; CAREY, M. A.; DUVALL, C. S.; JOHNSON, L.; LANE, K. M.; MCCLINTOCK, N.; MUNROE, D.; PAIN, R.; PROCTOR, J.; RHOADS, B. L.; ROBERTSON, M. M.; ROSSI, J.; SAYRE, N. F.; SIMON, G.; TADAKI, M.; VAN DYKE, C. Intervenção: Geografia Física Crítica (Intervention: Critical Physical Geography). Espaço Aberto, PPGG - UFRJ, Rio de Janeiro, v. 9, n.1, p. 77-94, 2019.

LIMA, R. N. S.; MARÇAL, M. S. Avaliação da condição geomorfológica da bacia do rio Macaé RJ a partir da metodologia de classificação dos estilos fluviais. Revista Brasileira de Geomorfologia, v. 14, n. 2, p. 171-179, 2013. 
MACKLIN, M. G.; LEWIN, J. The Rivers of Humankind. In: MYERS, S.; HEMSTOCK, S.; HANNA, E. (eds) Science, Faith and the Climate Crisis. Emerald Publishing Limited, p. 29-46, 2020. doi: https://doi.org/10.1108/978-1-83982-984-020201005

MAYER, N. The Cheonggyecheon River Restoration Project, Seoul, South Korea. Sustainability Writer, 2012. Disponível em: <https://sustainabilitywriter.wordpress.com/2012/07/04/thecheonggyecheon-river-restoration-project-seoul-south-korea/>. Acesso> 15 set. 2020.

MELLO, E. V. Alterações tecnogênicas em sistemas fluviais no município de Volta Redonda. 2006. 168 f. Dissertação (Mestrado em Geografia), Programa de Pós-Graduação em Geografia. Universidade Federal do Rio de Janeiro (PPGG/UFRJ), Rio de Janeiro, 2006.

MONTGOMERY, D. R.; BUFFINGTON, J. M. Channel-reach morphology in mountain drainage basins. GSA Bulletin, v. 109, n. 5; p. 596-611, 1997.

NETTO, C. M.; GUISSO, S. M.; SCHAFFER, L. J. Avaliação da destinação final do esgoto doméstico na região alta da bacia hidrográfica do rio Santa Maria da Vitória - ES/BRASIL. In: X CONGRESSO BRASILEIRO DE GESTÃo AMBIENTAL, Novembro, 2019, Fortaleza, CE. Anais... Fortaleza: 2019. 10 p.

NEGRÃO, A. P.; RAMOS, R. R.; MELLO, C. L.; SANSON, M. S. Mapa geológico do cenozoico da região da bacia de Volta Redonda (RJ, segmento central do Rifte Continental do Sudeste do Brasil): identificação de novos grabens e ocorrências descontínuas, e caracterização de estágios tectonossedimentares. Brazilian Journal of Geology, v. 45, p. 273-291, 2015.

OLIVEIRA, A. M. S. Depósitos tecnogênicos e assoreamento em reservatórios: exemplo do reservatório de Capivara, rio Paranapanema, SPIPR. 1994. 211 f. Tese (Doutorado em Geografia) - Faculdade de Filosofia e Ciências Humanas. Universidade de São Paulo (FFLCH/USP), São Paulo, 1994.

OliVEIRA, A. M. S.; BRANNSTROM, C.; NOlAsco, M. C.; PELOGGIA, A. U. G.; PEIXOTO, M. N. O.; COLTRINARI, L.; Tecnógeno: registros da ação geológica do homem. In: SOUZA, C.R.; SUGUIO, K.; OLIVEIRA, A.M.S.; OLIVEIRA, P.E. (orgs.) Quaternário do Brasil. São Paulo: ABEQUA/FAPESP, p. 363-378, 2005.

OLIVEIRA, S. A.; PEIXOTO, M. N. O.; MELLO, E. V. Lugares de perigo na cidade do aço: uma discussão sobre geotecnogênese, vulnerabilidade e risco ambiental em Volta Redonda (RJ). In: XI ENCONTRO DA ANPEGE. Anais... Presidente Prudente, 2015. ISSN 2175-8875. Disponível em www.enanpege.ggf.br/2015/ anais. Acesso em: jul. 2017.

OLIVEIRA, A. M. S.; PELOGGIA, A. U. F. The Anthropocene and the Technogene: stratigraphic temporal implications of the geological action of humankind. Quaternary and Environmental Geosciences, v. 5, n. 2, p. 103-111, 2014.

OLIVEIRA, E. L. A.; RECKZIEGEL, B. W.; ROBAINA, L. E. S. Modificações na morfologia dos canais de drenagem da bacia hidrográfica do Arroio Cadena, Santa Maria/RS. Revista RA'E GA, n. 11, p. 103-113, 2006.

PALMER, M. A.; BERNHARDT, E. S.; ALLAN, J. D.; LAKE, P. S.; ALEXANDER, G.; BROOKS, S.; CARR, J.; CLAYTON, S.; DAHM, C. N.; FLLSTAD SHAH, J.; GALAT, D. L.; LOSS, S. G.; GOODWIN, P.; HART, D. D.; HASSETT, B.; JENKINSON, R.; KONDOLF, G. M.; LAVE, R.; 
MEYER, J. L.; O'DONNELL, T. K.; PAGANO, L.; SUDDUTH, E. Standards for ecologically successful river restoration. Journal of Applied Ecology, v. 42, p. 208-217, 2005.

PARSONS, M.; THOMS, M. C.; FLOTEMERSCH, J.; REID, M. Monitoring the resilience of rivers as social-ecological systems: a paradigma shift for river assessment in the twenty-first century. In: GILVEAR, D. J.; GREENWOOD, M. T.; THOMS, M. C.; WOOD, P. J. (editores). River Science: Research and Management for the 21st Century. John Wiley \& Sons, Ltd, p. 197-220, 2016.

PELOGGIA, A. U. G. A ação do homem enquanto ponto fundamental da geologia do Tecnógeno: proposição teórica básica e discussão acerca do caso do município de São Paulo. Revista Brasileira de Geociências, v. 27, n. 3, p. 257-268, 1997.

PELOGGIA, A. U. G. O que produzimos sob nossos pés? Uma revisão comparativa dos conceitos fundamentais referentes a solos e terrenos antropogênicos. Revista UNG - Geociências, v. 16, n. 1, p. $102-127,2017$.

PELOGGIA, A. U. G. Geological classification and mapping of technogenic (artificial) ground: a comparative analysis. Revista do Instituto Geológico, v. 39, n. 2, p. 1-15, 2018.

PELOGGIA, A. U. G.; SAAD, A. R.; SILVA, R. V.; QUEIROZ, W. Processos de formação de terrenos e relevos tecnogênicos correlativos à urbanização: análise morfoestratigráfica e geoambiental aplicada na bacia do Córrego Água Branca, Itaquaquecetuba (RMSP). Revista Brasileira de Geomorfologia, v. 19, n. 2, p. 245-265, 2018.

PELOGGIA, A. U. G.; SILVA, E. C. N.; NUNES, J. O. R. Technogenic landforms: conceptual framework and application to geomorphologic mapping of artificial ground and landscape as transformed by human geological action. Quaternary and Environmental Geosciences, v.5, n. 2, p. 67-81, 2014.

REZENDE, O. R. Morro do Bumba 6 anos: revisitando a tragédia. Anais do XVIII Encontro Nacional de Geógrafos, 2016. São Luís, 2016. 11 p. Disponível em: <http://www.eng2016.agb.org.br/resources/anais/7/1467816862 ARQUIVO MorrodoBumba 6anos.pdf>. Acesso em: 15 set. 2020.

RINALDI, M.; GURNELL, A. M.; GONZÁLEZ DEL TÁNAGO, M.; BUSSETINI, M.; HENDRIKS, D. Classification of river morphology and hydrology to support management and restoration. Aquatic Sciences, v. 78, p. 17-33, 2016.

RODRIGUES, C. Morfologia original e morfologia antropogênica na definição de unidade espaciais de planejamento urbano: exemplo na metrópole paulista. Revista do Departamento de Geografia, v. 17, p. 101-111, 2005.

RODRIGUES, C.; MOROZ-CACCIA GOUVEIA, I. C.; LUZ, R. A.; VENEZIANI, Y.; SIMAS, I. T. H.; SILVA, J. P. Antropoceno e mudanças geomorfológicas: sistemas fluviais no processo centenário de urbanização de São Paulo. Revista do Instituto Geológico, v. 40, n. 1, p. 105123, 2019.

ROSGEN, D. L. A classification of natural rivers. Catena, v. 22, p. 169-199, 1994. 
SANTOS FILHO, R. D. Antropogeomorfologia Urbana. In: GUERRA, A. J. T. (org). Geomorfologia Urbana. Rio de Janeiro: Bertrand Brasil, p. 227-246, 2011.

SCORPIO, V.; AUCELLI, P.P.C; GIANO, S.I.; PISANO, L.; ROBUSTELLI, G.; ROSSKOPF, C.M.; SCHIATTARELLA, M. River channel adjustments in Southern Italy over the past 150 years and implications for channel recovery. Geomorphology, v. 251, p. 77-90, 2015.

SILVA-SÁNCHEZ, S.; JACOBI, P. R. Políticas de recuperação de rios urbanos na cidade de São Paulo. Estudos Urbanos e Regionais, v. 14, n. 2, nov. 2012.

SOUZA, M. L. O que é Geografia Ambiental?. Ambientes, v. 1, n. 1, p. 14-37, 2019.

TORRES, H. G. Desigualdade ambiental na cidade de São Paulo. 1997. 255 f. Tese (Doutorado em Ciências Sociais) - Instituto de Filosofia e Ciências Humanas, Universidade Estadual de Campinas, Campinas, 1997.

URBAN, M. A. In Defense of Crappy Landscapes (Core tenet \#1). In: LAVE, R.; BIERMANN, C.; LANE, S. N. (eds) The Palgrave Handbook of Critical Physical Geography, Palgrave Macmillan, Cham, 2018. Doi: <https://doi.org/10.1007/978-3-319-71461-5 3>.

WHEATON, J. M.; FRYIRS, K. A.; BRIERLEY, G.; BANGEN, S. G.; BOUWES, N.; O'BRIEN, G. Geomorphic mapping and taxonomy of fluvial landforms. Geomorphology, v. 248, p. 273295, 2015.

WYRICK, J. R.; PASTERNACK, G. B.; Geospatial organization of fluvial landforms in a gravelcobble river: Beyond the rifle-pool couplet. Geomorphology, v. 213, p.48-65, 2014.

WYRICK, J. R.; SENTER, A. E.; PASTERNACK, G. B. Revealing the natural complexity of fluvial morphology through 2D hydrodynamic delineation of river landforms. Geomorphology, v. 210, p. 14-22, 2014. 